- Short communication

\title{
INFLUENCE OF THICKNESS ON THE OPTICAL PROPERTIES OF Sb DOPED ZnO THIN FILMS
}

\author{
E. HOQ, M.R.A. BHUIYAN* AND J. BEGUM ${ }^{1}$ \\ Department of Applied Physics, Electronics and Communication Engineering, Islamic \\ University, Kushtia 7003, Bangladesh
}

\begin{abstract}
$\mathrm{Sb}$ doped $\mathrm{ZnO}$ thin films having various thicknesses have been prepared onto glass substrate by using thermal evaporation method. The atomic compositions of the grown films have been determined by Energy Dispersive Analysis of X-ray (EDAX) method. The optical properties were measured by using a UV-VIS-NIR spectrophotometer (300 to $2500 \mathrm{~nm}$ ). The EDAX analysis revealed that $\mathrm{Sb}$ is doped into the $\mathrm{ZnO}$ films. Optical properties showed high absorption coefficient $\left(\sim 10^{5} / \mathrm{cm}\right)$ that direct allowed transition band gap. The optical band gap of the $\mathrm{ZnO}$ thin films became reduced due to the doping of $\mathrm{Sb}$.
\end{abstract}

Key words: $\mathrm{Sb}$ doped $\mathrm{ZnO}$ thin films, Thickness, Composition, Optical properties

$\mathrm{ZnO}$ is one of the most promising materials that exhibit a large exciton binding energy and direct band gap of $3.3 \mathrm{eV}$. It is undoubtedly a good candidate to produce light emission in the visible and UV ranges but due to the doping of $\mathrm{Sb}$ into the $\mathrm{ZnO}$ the optical band gap and light emission range is changed to visible and near inferred region (Benelmadjat et al. 2010). The carrier recombination process in $\mathrm{ZnO}$ and its doped form increases the interest for optoelectronics applications (Fay et al. 2007, Zeng et al. 2003). Due to the doping of $\mathrm{Sb}$ into $\mathrm{ZnO}$ different properties of $\mathrm{ZnO}$ thin films are changed like compositional, band gap energy, reflectance, absorption range with photon energy etc. (Look 2001). In the present study, the influence of thickness on the optical properties of $\mathrm{Sb}$ doped $\mathrm{ZnO}$ thin films were investigated.

Preliminary (10\%) black Sb powder of 1.425 gm and (90\%) white $\mathrm{ZnO}$ powder of $8.575 \mathrm{gm}$ was taken by using electronic balance. The composition of $\mathrm{Sb}$ doped $\mathrm{ZnO}$ thin films have been prepared by using the solid-state reaction technique.

The EDAX spectrum of $\mathrm{Sb}$ doped $\mathrm{ZnO}$ thin films are shown in Fig. 1. These show reasonably identical values $( \pm 0.02$ at. \%) that ascertains the compositional homogeneity of the films. In our observation the peaks of O-Ka, Zn-La, Sb-La, Sb-Lb, Zn-Ka and Zn-

\footnotetext{
* Corresponding author:<mrab_iu@yahoo.com>.

${ }^{1}$ Experimental Physics Division, Atomic Energy Centre, GPO Box 164, Dhaka 1000, Bangladesh.
} 
$\mathrm{Kb}$ were present at $0.55,1.00,3.64,4.00,8.71$ and $9.62 \mathrm{KeV}$, respectively. Other peaks of $\mathrm{Zn}-\mathrm{L} 1, \mathrm{Sb}-\mathrm{L} 1$ and $\mathrm{Sb}-\mathrm{Lg}$ were present at $0.8,3.3$ and $4.2 \mathrm{KeV}$, respectively. Additional peaks of C-Ka, Mg-Ka, Mo-L1, Mo-La, Mo-Lg and Al-Ka were also present at $0.196,1.284,2.051,2.421$ and $2.815 \mathrm{KeV}$, respectively. It is confirmed that $\mathrm{Sb}$ is doped into $\mathrm{ZnO}$ thin films. Similar results were also reported by other researchers (Wang et al. 2006, Zhao et al. 2008)

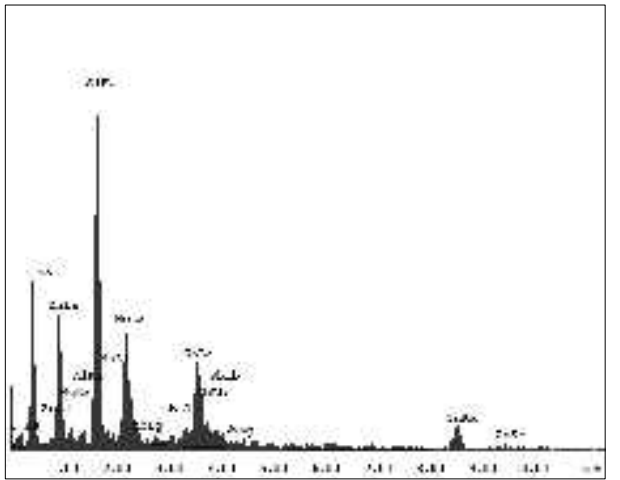

Fig. 1. Typical EDAX spectrum of $\mathrm{Sb}$ doped $\mathrm{ZnO}$ thin films.

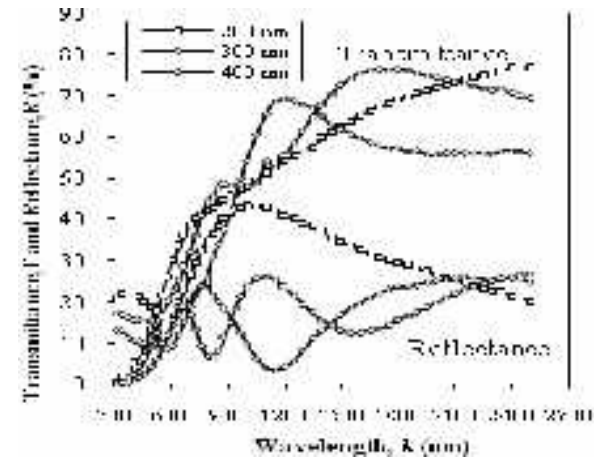

Fig. 2. Dependence of optical transmittance and reflectance on wavelength for $\mathrm{Sb}$ doped $\mathrm{ZnO}$ thin films having different thicknesses.

The transmittance and reflectance spectra of $\mathrm{Sb}$ doped $\mathrm{ZnO}$ thin films with different thicknesses having $50^{\circ} \mathrm{C}$ substrate temperature are shown in Fig. 2. The transmittance spectra show two distinct regions: one for long wavelength with high transmittance and another for short wavelength where transmittance decreases abruptly down to almost zero. The maximum transmittance of the films was $\sim 85 \%$ in the near inferred region and $\sim 50 \%$ in the visible region. It was observed that the transmittance decreased at short wavelength and increased at long wavelength with the increase in the film thickness. This happened due to lattice disorder, internal stress, discontinuity of the films, refractive index difference between $\mathrm{Sb}$ and $\mathrm{ZnO}$ and interstice radius difference between $\mathrm{Sb}^{3+}$ and $\mathrm{ZnO}$ (Zeng et al. 2003). It is observed that the reflectance spectra shows interference pattern with distinct peaks and valleys that small in the UV region.

Fig. 3 shows a significantly high absorption coefficient $\left(\approx 10^{5} / \mathrm{cm}\right)$ above $2.6 \mathrm{eV}$ for $\mathrm{Sb}$ doped $\mathrm{ZnO}$ thin films. The analysis of the absorption coefficient, $\alpha$ above the fundamental edge shows that the rise of $\alpha$ in the photon energy range $2.8 \leq \mathrm{h} v \leq 4.00 \mathrm{eV}$ follows a relation for an allowed direct interband transition (Patel et al. 1987) described by

$$
\alpha=\frac{A_{1}}{h v}\left[h v-E_{g_{1}}\right]^{1 / 2}
$$


where, $E_{g l}$ is the band gap energy of the interband transition and $A_{I}$ is a parameter that depends on the probability of transition and the refractive index of the material.

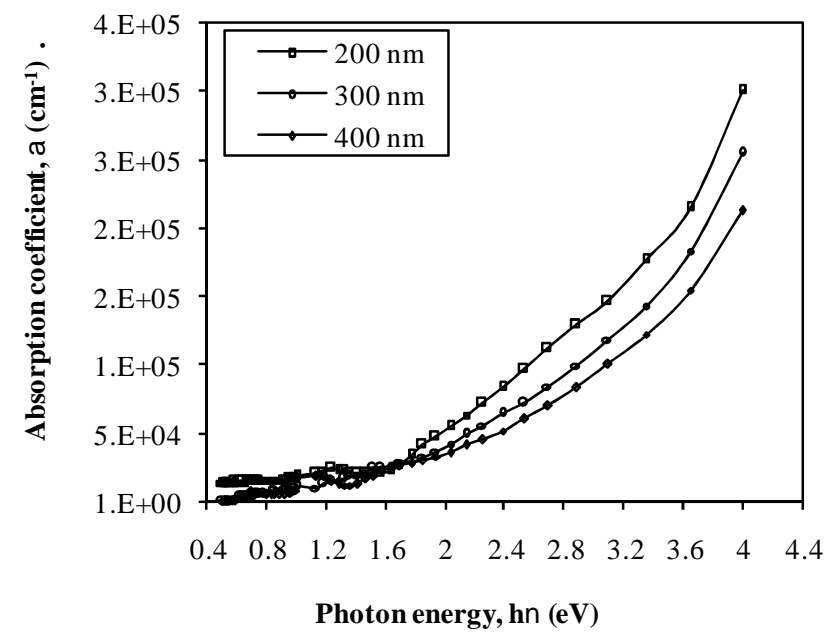

Fig. 3. Dependence of absorption coefficients on photon energy for $\mathrm{Sb}$ doped $\mathrm{ZnO}$ thin films having different thicknesses.

It was observed that the values of absorption coefficient decreasd with the increase in the film thickness which conforms reasonably well (Nadeem et al. 2000). The band gap energy and the value of $A_{1}$ were found out from the plot of $(\alpha h v)^{2}$ versus $h v$. Extrapolation of the linear portion of the curve to $(\alpha h v)^{2}=0$ gives the optical band gap. This indicates direct allowed band gap because the obtained straight line in the photon energy range $(2.695 \leq \mathrm{hv} \leq 4 \mathrm{eV})$. It was found that the band gap energy decreased from 2.989 to $2.779 \mathrm{eV}$ as the film thickness increased from 200 to $400 \mathrm{~nm}$. The calculated optical parameters are summarized in Table 1.

Table 1. Optical parameters of Sb doped $\mathrm{ZnO}$ thin films.

\begin{tabular}{cll}
\hline Thickness $(\mathrm{nm})$ & $\mathrm{Eg}(\mathrm{eV})$ & $\mathrm{A}\left(\mathrm{cm}^{\mathrm{eV}}{ }^{1 / 2}\right)$ \\
\hline 200 & 2.989 & $9.29 \times 10^{5}$ \\
300 & 2.929 & $9.08 \times 10^{5}$ \\
400 & 2.779 & $8.41 \times 10^{5}$ \\
\hline
\end{tabular}

It is concluded that thickness may produce a desired band gap of $\mathrm{Sb}$ doped $\mathrm{ZnO}$ material having an energy band gap between 2.779 and $2.989 \mathrm{eV}$.

The authors are grateful to the authority of Atomic Energy Centre, Dhaka for allowing them to utilize their laboratory facilities. 


\section{REFERENCES}

Benelmadjat, H., N. Touka, B. Harieche, B. Boudine, O. Halimi and M. Sebais. 2010. Study of structural and optical properties of $\mathrm{Sb}$ doped $\mathrm{ZnO}$ thin films deposited by spin coating method. Optical Materials 32: 764-767.

Fay, S., J. Steinhauser, N. Oliveira, E. Vallat-Sauvain and C. Ballif. 2007. Opto-electronic properties of rough LP-CVD ZnO:B for use as TCO in thin-film silicon solar cells. Thin Solid films 515: 8558-8561.

Look, D.C. 2001. Recent advances in ZnO materials and devices. Materials Science Engineering:B 80: $383-387$.

Nadeem, M.Y. and W. Ahmed. 2000. Optical properties of ZnS thin films. Turk. J. Phys. 24: 651659.

Patel, S.M. and V.G. Kapale. 1987. Optical properties of $\mathrm{AgGaSe}_{2}$ thin films. Thin Solid films 148: 143-148.

Wang, P., N. Chen, Z. Yin, F. Yang and C. Peng. 2006. Fabrication and properties of Sb-doped $\mathrm{ZnO}$ thin films grown by radio frequency (RF) magnetron sputtering. J. Crys. Growth 290: 56-60.

Zeng, D.W., C.S. Xie, B.L. Zhu, W.L. Song and A.H. Wang. 2003. Synthesis and characteristics of Sb-doped ZnO nanoparticles. Materials Science and Engineering:B 104: 68-72.

Zhao, J.Z., H.W. Liang, J.C. Sun, Q.J. Feng, J.M. Bian, Z.W. Zhao, H.Q. Zhang, L.Z. Hu and G.T. Du. 2008. p-type Sb-doped $\mathrm{ZnO}$ thin films prepared by metallorganic chemical vapor deposition using metallorganic dopant. Electrochem. Solid-State Lett. 11: 323-332. 